УДК 94(470+571)

DOI 10.18413/2687-0967-2020-47-2-318-326

\title{
ДВАДЦАТЬ ЧЕТЫРЕ ПОПЕЧИТЕЛЯ НАХИЧЕВАНИ-НА-ДОНУ (ИЗ ИСТОРИИ ОДНОГО ПОЛУЗАБЫТОГО ОРГАНА) ${ }^{31}$

\author{
TWENTY-FOUR TRUSTEES OF NAKHICHEVANI-ON-DON \\ (FROM THE HISTORY OF ONE SEMI-FORGOTTEN AUTHORITY)
}

\author{
Л.В. Батиев \\ L.V. Batiev \\ Южный научный центр Российской академии наук, \\ Россия, 344006, г. Ростов-на-Дону, пр. Чехова, 41 \\ Southern Scientific Center of the Russian Academy of Sciences, \\ 41 Chekhov Ave, Rostov-on-Don, 344006, Russia \\ E-mail: batiev@ssc-ras.ru
}

\begin{abstract}
Аннотация
Статья посвящена особенностям процесса трансформации системы армянского самоуправления в Нахичевани-на-Дону в середине XIX в. Исследование основано на принципах научности, историзма, объективности и междисциплинарности. Это позволило изучить преобразования в совокупности их многообразия и сложности, учитывая причинно-следственные связи и особенности определенной исторической обстановки. На основе методов таких наук, как история, этнология и юриспруденция, с использованием архивных материалов рассмотрена история коллегии двадцати четырех попечителей (местного аналога городской думы). Установлено, что этот орган в первой половине XIX в. потерял свое значение и практически перестал созываться. Вновь он появляется в 1866 г. в ходе реформирования городского самоуправления уже в качестве вспомогательного совещательного органа при городском голове. Результатом реформ стало лишение магистрата Нахичевани практически всех функций и его упразднение. Основным органом самоуправления до проведения общей городской реформы становится городской голова.
\end{abstract}

\begin{abstract}
The article is devoted to the features of the process of transformation of the system of Armenian self-government in Nakhichevan-on-Don in the middle of the XIX century. The study is based on the principles of science, historicism, objectivity, and interdisciplinarity. This allowed us to study the transformations in the aggregate of their diversity and complexity, taking into account causal relationships and the characteristics of a particular historical situation. Based on the methods of such sciences as history, ethnology, and jurisprudence, using archive materials, the history of the council of twenty-four trustees (a local analog of the city council) is analyzed. It is established that this council in the first half of the XIX century lost its significance and almost ceased to convene. It reappears in 1866 during the reform of city self-government as an auxiliary deliberative body under the mayor. The reforms resulted in the deprivation of the magistrate of Nakhichevan of almost all functions and its abolition. Before the general city reform, the mayor becomes the main body of self-government.
\end{abstract}

Ключевые слова: Нахичевань-на-Дону, самоуправление, попечители (опекуны), магистрат, городской голова, дума, реформа.

Keywords: Nakhichevan-on-Don, self-government, trustees (guardians), magistrate, city head, thought, reform.

\footnotetext{
${ }^{31}$ Статья выполнена при финансовой поддержке гранта РГНФ (РФФИ) 18-59-05004.
} 
История городского самоуправления в дореформенной России сегодня становится популярной темой исследований, реализуясь в монографиях, диссертациях и журнальных статьях. Однако на исторической карте страны остается еще много белых пятен. Одну из них составляет специфическая организация самоуправления Нахичеванского округа, объединявшего армян-переселенцев из Крыма, которые основали в 1779 город НорНахичеван (с 1838 г. - Нахичеван-на-Дону [ПСЗ-II. Т. 13. 10976]) и пять армянских сел в его округе. Даже в фундаментальном труде В.Б. Бархударяна вопросам самоуправления Нахичевани в 1780-1917 гг. посвящен всего лишь один небольшой параграф [Бархударян, 1996, 47-61]. Неудивительно, что за пределами исследования остались многие особенные моменты эволюции органов общественного самоуправления. К их числу можно отнести процесс реформирования управления Нахичеванским округом, закончившийся полным упразднением остатков автономии, дарованной в 1779 г. Отдельные сведения по истории самоуправления можно почерпнуть из брошюры М. Богданяна [Богданян, 1989], мемуаров Келле-Шагинова [Келле-Шагинов, 2012; Келле-Шагинов, 2014], энциклопедии В.С. Сидорова [Сидоров, 1994-1999] и «летописи» В.В. Смирнова [Смирнов, 2018]. Наибольший интерес для исследователя представляют непереведенные на русский язык сочинения Е. Шахазиза [Шахазиз, 1903] и Г. Патканяна [Патканян, 1917]. Изложение статей Армянского судебника, которым руководствовались в Нахичевани, дано в книге К. Алексеева [Алексеев, 1870].

Цель данной статьи - анализ особенностей процесса трансформации системы армянского самоуправления в Нахичевани-на-Дону в середине XIX в. Исследование основано на принципах научности, историзма, объективности и междисциплинарности, что позволило изучить преобразования в совокупности их многообразия и сложности, учитывая причинно-следственные связи и особенности определенной исторической обстановки, на основе таких наук, как история, этнология и юриспруденция. Материалом для исследования послужили опубликованные источники и сочинения (в том числе непереведенные на русский язык), законодательство Российской империи, мемуары и статистические издания и справочники, а также неопубликованные источники (дела Национального архива Армении и Российского государственного исторического архива).

Основным органом самоуправления Нахичеванского округа являлся армянский магистрат [Батиев, Казаров, 2018, с. 518-527], образованный 14 января 1780 г. на основании «Жалованной грамоты вышедшим из Крыма христианам армянского закона», утвержденной императрицей Екатериной II 14 ноября 1779 г. [ПСЗ-I. Т. 20. № 14942]. Председатель и четыре заседателя магистрата выполняли функции суда, полиции и общего управления городом и пятью армянскими селами [Келле-Шагинов, 2012]. Такое соединение властей в одном органе являлось особенностью армянской колонии, и нахичеванцы крепко держались за него, поскольку оно обеспечивало функционирование всей колонии как единого организма.

В соответствии с «Грамотой на права и выгоды городам Российской империи» от 21 апреля 1785 г. [ПС3-І. Т. 22, № 16187] в Нахичевани также предусматривалось создание двухуровневой городской думы. Однако новая модель управления в армянской колонии не прижилась в силу ее сложности и непривычности. Как указывал Е. Шахазиз, чтобы привести в порядок управление города и решить проблемы, возникшие в результате непонимания смысла закона, нахичеванцы обратились к своему духовному пастырю архиепископу Иосифу Аргутинскому. Система управления была переформатирована на основании составленной архиепископом «Конвенции единства» («Дашнадрутюн миабанутян»). Новый «устав» города из тринадцати статей был напечатан в типографии монастыря Сурб Хач и распространен среди горожан. Но этот документ, как указывал Е. Шахазиз, восстановивший по разрозненным источникам почти весь его текст, по сути, представляет клятву попечителей и содержит мало конкретных указаний на их полномочия и порядок работы. Новая городская дума из двадцати четырех попечителей была избрана 26 мая 1795 г. Под председательством городского головы попечители совместно с магистратом должны 
были рассматривать и решать все основные вопросы управления городом и округом. Заседания проводились раз в неделю по субботам и длились с 8 утра до 12 часов дня. Присутствие всех попечителей на заседаниях было обязательным. Уважительной причиной отсутствия считались болезни и важные дела, о чем отсутствующий должен был сообщить заранее, иначе после двух-трех предупреждений он изгонялся из совета как не выполняющий свои обязанности, и на его место избирался новый. Должности попечителя лишались также те, кто хоть и ходил на заседания, но безразлично и беззаботно относился к должности. Предметом обсуждения были все вопросы городской жизни, счета, которые должен был представлять городской голова о доходах и расходах города за трехлетний период, а также вопросы народной морали. Решения принимались большинством голосов. Вопросы, которые требовали дополнительного ознакомления и обсуждения, заносились в протокол за подписями попечителей, а после выносились на собрание всего общества [Шахазиз, 1903, с. 14-19]. Таким образом была создана более или менее сбалансированная система властей из трех основных органов - двадцати четырех попечителей (городской думы), осуществлявших совещательные и контрольные функции, магистрата, который реализовал полномочия в сфере общего управления городом и округом, а также судебнополицейские функции, и городского головы, чье ведение ограничивалось первоначально только сбором и расходованием денежных средств города.

Неизвестно точно, как долго функционировал совет двадцати четырех попечителей, поскольку на практике происходило его постепенное «угасание». Со временем городской голова становился все более самостоятельной фигурой, а избираемые обществом городские попечители лишь содействовали ему в исполнении его обязанностей. Формальным основанием для такого превращения являлось отсутствие какой-либо нормативной определенности (в законодательстве или общественном приговоре) по поводу прав и обязанностей головы. Поэтому, как заключал сенатор М.Н. Жемчужников, ревизовавший в 1844 г. Нахичеванский округ, «пространство власти сего почетного лица зависит от личных его качеств и от уважения, которым он пользуется в Нахичеванском округе» ${ }^{32}$.

Пользуясь общим падением авторитета городских властей среди горожан и их безразличием к вопросам формирования и деятельности двадцати четырех попечителей, а также нежеланием служить на выборных должностях, городской голова приобрел самостоятельность и независимость от других органов нахичеванского самоуправления. Он перестал отчитываться перед попечителями, подчиняясь в этом вопросе Таганрогскому градоначальству. У попечителей осталось лишь право совета городскому голове, который, пользуясь обстоятельством, старался стать совершенным автократом, действуя своевольно во всех делах, не принимая во внимание мнение попечителей, даже не приглашая их на совет, а часто советуясь с ними лишь для формальности [Шахазиз, 1903, с. 32-34].

Последнее известное упоминание о попечителях связано с совместным обращением магистрата, попечителей и городского головы к таганрогскому градоначальнику в 1837 г. за разрешением избрать дополнительно двух «смотрителей за благоустройством» ${ }^{33}$. Но из информации, приведенной сенатором М.Н. Жемчужниковым, трудно понять, были ли в это время попечители самостоятельны в своих решениях, или же просто ими воспользовались для придания прошению большей убедительности.

К середине XIX в. «городская дума» вообще перестает собираться и остается только в памяти нахичеванцев [Келле-Шагинов, 2014, с. 297; Шахазиз, 1903, с. 32-34], хотя в ответах из магистрата на запросы Таганрогского градоначальства в 1854 г. все еще указывалось, что в составе магистрата заключаются в том числе и городская дума, и градской глава ${ }^{34}$.

\footnotetext{
${ }^{32}$ Российский государственный исторический архив (РГИА). Ф. 1405. Оп. 42. Д. 6812. Л. 79-79 об.

${ }^{33}$ РГИА. Ф. 1405. Оп. 42. Д. 6812. Л. 43-43 об.

${ }^{34}$ Национальный архив Армении (НАА). Ф. 139. Оп. 1. Д. 87. Л. 20-20 об.
} 
В связи с предложенными правительством реформами городского самоуправления в Нахичевани-на-Дону возникла идея возрождения совета опекунов. В середине 1850-х годов в правительственных кругах продвигалась идея учреждения городских дум в городах Новороссийского края и Бессарабской области. Для оценки всех предложений и решения вопроса о целесообразности учреждения городских дум «смотря по положению каждой местности, по ее населению, торговле и т. п. обстоятельствам» министерство внутренних дел запросило с мест сведения и соображения о «необходимости устройства общественного управления в заштатных городах, посадах и местечках». Соответствующее предписание от состоящего в должности таганрогского градоначальника графа Н.В. Адлерберга 13 января 1854 г. получили и городской голова с нахичеванским армянским магистратом ${ }^{35}$. Из повторного предписания, полученного в Нахичевани 12 мая того же года, явствовало, что в правительстве рассматривалась также идея передачи дел всех магистратов и судебных ратуш в ведомство уездных судов ${ }^{36}$. Соединение в армянском магистрате трех разновидностей местной власти - «по внутреннему управлению, по судебному управлению и по полицейскому управлению» - противоречило ст. 303 «Устава о службе по выборам городских обывателей» Свода законов Российской империи [Свод законов Российской империи, Т. 3]. О недопустимом «смешении несоединимых властей» писали и позднее в официальных изданиях, подготовленных к проведению судебной реформы [Судебно-статистические сведения, 1866, с. 56].

Для Нахичевани предлагаемая реформа означала коренную ломку сложившейся системы управления и суда. Поэтому в ответе, подготовленном 14 мая 1854 г., городской голова и магистрат указали, в частности, на недостаточность средств в городском бюджете. Но в то же время городское руководство верноподданнически заявляло, что при решении о необходимости реформ «армяне, быв убеждены, что установления правительства составляют отечественное благо, всегда готовы дополнять недостаток сказанных доходов добровольною складкою» 37 .

По всей видимости, до начала мая 1857 г. шла переписка между региональными и центральными органами по поводу целесообразности реформ в Нахичевани, пока наконец 7 мая 1857 г. Таганрогский градоначальник контр-адмирал Н.А. Лавров не предписал нахичеванскому армянскому магистрату и городскому голове «немедленно собрать городское общество и в видах правильного заведывания городским хозяйством войти в соображение, не следует ли образовать в Нахичевани на общих правах городскую думу, и если это будет признано возможным и необходимым, то представить на дальнейшее с моей стороны соображение, самый проект штата» ${ }^{38}$, которая завершилась тем, что решение вопроса было возложено на само нахичеванское общество.

Собрание было назначено на 28 июня, для чего было 25 июня отослано письмо городскому голове с предложением уведомить магистрат об отзыве городского общества и, в случае положительного ответа, «представить и проект штата с объяснением, из каких источников предполагается производить отпуск суммы на содержание Думы» ${ }^{39}$. Городской голова С.Х. Аладжалов четвертого июля препроводил в магистрат общественный приговор, вынесенный обществом. В нем нахичеванцы вместе с представителями пяти армянских сел, ссылаясь на грамоту Екатерины II, в которой речь идет о магистрате, а не городской думе, приговорили «предоставить магистрату совместно с градским головою ходатайствовать о оставлении навсегда установленного предками нашими порядка по управлению городским хозяйством, существующего более полувека, и по убеждению нашему ручающегося в удовлетворительных и полезных результатах и на будущее время; Но чтобы доставить город-

\footnotetext{
${ }^{35}$ НАА. Ф. 139. Оп. 1. Д. 87. Л. 4-4 об.

${ }^{36}$ НАА. Ф. 139. Оп. 1. Д. 87. Л. 14 об.

${ }^{37}$ НАА. Ф. 139. Оп. 1. Д. 87. Л. 18 об. -20 об.

${ }^{38}$ НАА. Ф. 139. Оп. 1. Д. 87. Л. 23-23 об.

${ }^{39}$ НАА. Ф. 139. Оп. 1. Д. 87. Л. 25-25 об.
} 
скому голове возможность к более успешному исполнению всех обязанностей на нем имеющих, и которые в настоящее время от развития городской промышленности заметно увеличились, общество может и полагает необходимым назначить из среды себя 24 опекунов общества для советов по делам общественным и в помощь городскому голове 4 граждан, которые будут находиться под непосредственным его распоряжением для возложения на них различных поручений до городского хозяйства относящихся» ${ }^{40}$.

Приговор нахичеванского общества последствий в ближайшие несколько лет не имел. Но 31 августа 1862 г. в нахичеванском магистрате было получено предписание екатеринославского вице-губернатора, в котором, со ссылкой на решение министра внутренних дел, указывалось: «немедленно составить требуемые соображения относительно улучшения городского общественного управления и представить ко мне ... непременно не позже 20 наступающего сентября» ${ }^{41}$.

13 сентября 1862 года городской голова К. Гайрабетов отвечал магистрату по поводу предписания: «предмет этот, относящийся ко всему городскому обществу, был мною предлагаем на обсуждение граждан города Нахичевана, и составленный ими вследствие того приговор представлен мною его превосходительству при рапорте от 13-го сего сентября» ${ }^{42}$. Смысл ответа не отличался от предыдущего: нахичеванское общество не нашло «существенной надобности и пользы в перемене сего существующего ныне учреждения» ${ }^{43}$.

Тем не менее идея реформирования нахичеванского самоуправления не была забыта властями. Вновь этот вопрос был поднят действительным статским советником М.К. Катакази, состоящим при Новороссийском и Бессарабском генерал-губернаторе П.Е. Коцебу. 14 февраля 1864 г. он затребовал сведения о том, что было сделано по итогам общественного приговора 1857 г. ${ }^{44}$. Сам М.К. Катакази полагал целесообразным впредь до учреждения новой системы согласиться с мнением городского общества об избрании из нахичеванцев двадцати четырех опекунов в качестве советников городского головы, а также четырех граждан собственно в распоряжение городского головы, о чем информировал свое руководство. Предложение чиновника было принято в качестве временной меры, и 28 декабря 1865 г. генерал-губернатор распорядился о реализации предложенных мер ${ }^{45}$.

В архиве магистрата сохранились некоторые сведения относительно выборов опекунов при городском голове. Так, 9 февраля 1866 г. городской голова К. Гайрабетов просил армянский магистрат: «как можно поспешнее доставить мне списки 1ㄹ, общества купцов и мещан, имеющих по закону право голоса в выборах и 2е судом и следствием вообще как дворян, так купцов и мещан» ${ }^{46}$. «Список жителям города Нахичевана всех сословий, составляющим наличное число домохозяев, имеющих право голоса на выборах ... вместе со списком нахичеванским купцам, мещанам и поселянам, состоящим под судом и следствием» по поручению магистрата был составлен мещанским старостой М. Абрамовым и отослан городскому голове ${ }^{47}$.

21 февраля 1866 г. городской голова получил от М.К. Катакази отношение за № 90, в котором был разъяснен порядок подготовки и проведения выборов. Нужно было «1 1 e число сего месяца пригласить дворян, домовладельцев и купечество для назначения из среди себя 75 человек избирателей. $2^{\mathrm{e}}$, на 25 число пригласить мещанское сословие для назначения из среди оного также 75 человек избирателей, и $3 \stackrel{\text { e }}{\text {, } 26}$ числа в общем уже собрании тех и других избирателей должно приступить к выбору опекунов и помощников» ${ }^{48}$.

\footnotetext{
${ }^{40}$ НАА. Ф. 139. Оп. 1. Д. 87. Л. 33-34 об.

${ }^{41}$ НАА. Ф. 139. Оп. 1. Д. 87. Л. 41-42 об.

${ }^{42}$ НАА. Ф. 139. Оп. 1. Д. 87. Л. 43.

${ }^{43}$ НАА. Ф. 139. Оп. 1. Д. 87. Л. 50 об.

${ }^{44}$ НАА. Ф. 139. Оп. 1. Д. 87. Л. 45-45 об.

${ }^{45}$ НАА. Ф. 139. Оп. 1. Д. 197. Л. 2-2об.

${ }^{46}$ НАА. Ф. 139. ОП. 1. Д. 191. Л. 79.

${ }^{47}$ НАА. Ф. 139. Оп. 1. Д. 191. Л. 80.

${ }^{48}$ НАА. Ф. 139. ОП. 1. Д. 191. Л. 81-81 об.
} 
Проведение выборов было назначено на 26 февраля в доме уездного училища. Соответствующие повестки об этом были разосланы в магистрат (с просьбой командировать полицейского заседателя для соблюдения тишины, благочиния и порядка, как при приводе избирателей к присяге в соборной церкви, после литургии и молебствия, так и при производстве выборов, к которым приглашались все члены магистрата), исправляющему должность стряпчего по городу Нахичевани, в городское Духовное правление ${ }^{49}$.

Следом за избранием опекунов и помощников городского головы в соответствии с указанием екатеринославского губернского правления ${ }^{50} 1$ июля 1866 г. прошли и выборы в шестигласную городскую думу ${ }^{51}$. Но ясности по поводу реформирования управления в Нахичевани не было. Екатеринославский губернатор 20 сентября 1866 г. запрашивал Новороссийского и Бессарабского генерал-губернатора «о том, следует ли в г. Нахичевани образовать городскую думу на общем основании или оставить ныне учрежденное там временное управление по заведыванию городским хозяйством». Этот вопрос был переадресован министру внутренних дел с присовокуплением мнения генерал-губернатора Новороссийского и Бессарабского. П.Е. Коцебу предлагал «разрешить оставить в г. Нахичевани в силе введенное там, по его распоряжению, временное общественное управление по заведыванию городским хозяйством, тем более что в непродолжительном времени ожидается введение в этом городе общественного управления на новых началах» ${ }^{52}$.

31 января 1867 г. Новороссийский и Бессарабский генерал-губернатор П.Е. Коцебу сообщил результаты переписки Екатеринославскому губернатору: министр внутренних дел П.А. Валуев 14 декабря 1866 г. уведомил П.Е. Коцебу, «что в виду предстоящего преобразования городского общественного управления, он, г. министр, не встречает препятствия к оставлению в г. Нахичевани заведывание делами общественного управления и городского хозяйства на существующих основаниях» ${ }^{53}$. Таким образом, новообразованная шестигласная дума так и не стала действующим органом местного управления.

Последний состав магистрата, избранный 15 ноября 1865 г. $^{54}$ на трехлетие (с 1866 г.), просуществовал дольше положенного срока. Но это было уже жалкое подобие когда-то главного органа самоуправления. В 1865 г., вопреки петициям армянской общины, решением генерал-губернатора полицейские функции армянского магистрата Нахичевани, вначале в качестве временной меры, были переданы полицейскому управлению Ростова. Армянские села Нахичеванского округа к этому времени уже находились в подчинении земств Ростова [Бархударян, 1996, с. 336]. А уже 27 февраля 1868 г. были высочайше утверждены новые штаты Ростовских (на Дону) уездного и городского полицейских управлений [ПСЗ-ІІ. СПб., 1868. Т. 43. № 45541]. Нахичевань с округом окончательно перешли в ведение Ростовского городского и уездного полицейских управлений [Батиев, 2018, № 3 (115), c. 3-16].

13 апреля 1866 г. были утверждены «Правила об упразднении магистратов и судебных ратуш», на реализацию требований которых был отведен двухмесячный срок со дня получения закона на местах [ПСЗ-ІІ. Т. 43. № 45541]. Распоряжение о реализации указа об упразднении магистрата и передаче всех судебных дел в уездный суд Екатеринославское губернское правление сделало 20 июня 1866 г. ${ }^{55}$. Но магистрат не был упразднен целиком и сразу. Официально и окончательно судебная часть его была упразднена с введением 30 апреля 1869 г. в действие в Екатеринославской губернии «Судебных уставов» 20 ноября 1864 г. ${ }^{56}$. Оставшаяся часть магистрата, за которой сохранились минимальные

\footnotetext{
${ }^{49}$ НАА. Ф. 139. Оп. 1. Д. 191. Л. 82-84.

${ }^{50}$ НАА. Ф. 139. ОП. 1. Д. 197. Л. 4.

${ }^{51}$ НАА. Ф. 139. Оп. 1. Д. 197. Л. 5-25.

${ }^{52}$ НАА. Ф. 139. Оп. 1. Д. 197. Л. 26-26 об.

${ }^{53}$ НАА. Ф. 139. Оп. 1. Д. 197. Л. 26-26 об.

${ }^{54}$ НАА. Ф. 139. Оп. 1. Д. 191. Л. 21, 22-23, 27-28.

${ }^{55}$ НАА. Ф. 139. Оп. 1. Д. 197. Л. 5-25.

${ }^{56}$ НАА. Ф. 139. Оп. 1. Д. 249. Л. 24.
} 
хозяйственные, опекунские и «распорядительные» полномочия, в июне 1870 г. была перемещена в «дом хозяйственного управления», а затем и вовсе присоединена к «временному управлению городским хозяйством» ${ }^{57}$. Передача дел магистрата из-за противодействия оставшихся его членов затянулась до ноября 1870 г., а сам магистрат (то, что от него осталось) был официально упразднен с 1 июля 1871 г.

До введения в Нахичевани в 1872 г. нового «Городового положения» 1870 г. и образования городской думы нового - общеимперского - образца в городе по распоряжению генерал-губернатора Новороссийского и Бессарабского действовало «временное управление по заведыванию городским хозяйством». Возглавил его городской голова, при котором и функционировал с правом совещательного голоса совет двадцати четырех опекунов (попечителей).

О деятельности опекунов на сегодня известно немного. Так, в связи с началом процедуры упразднения магистрата, согласно указу 13 апреля 1866 г. и необходимостью перевода на русский язык дел, «производящихся по армянскому отделению магистрата на армянском языке, цена иска коих превышает 500 руб. сер. (75-я ст. высочайше утвержденных 11 октября 1865 г. правил)», исправляющий должность стряпчего по г. Нахичевани запрашивал у городского головы, было ли проведено собрание городского общества для решения вопроса о дополнительной добровольной складке для финансирования необходимых расходов ${ }^{58}$. Собрание общества, не беря на себя ответственность, «постановило: предмет этот для первоначального попечителям городового общественного управления, не по обязанности на них возложенной, а как на передовых почетных лиц, особенно пользующихся нашим доверием, и заключение их, поэтому передать на дальнейшее наше распоряжение» ${ }^{59}$. В ответ на это обращение «опекуны Нахичеванского городского хозяйственного управления», объяснив, что их обязанность «состоит в обсуждении тех только вопросов, которые относятся к городовому общественному хозяйству - изысканию средств увеличения городовых доходов и к устройству хозяйственной части, то, как и выразило общество, не находя себя вправе судить о предложенном предмете, мы однакож изъявляем наше согласие к выполнению желания общества, но на том условии, что к нам не как опекунам, а как к членам общества и почтенным лицам из граждан» ${ }^{60}$.

Из переписки городского головы с магистратом относительно средств на содержание магистрата видно, что, например, в 1867 г. именно опекуны по Нахичеванскому городскому общественному управлению приняли постановление 12 сентября 1867 г. «по предмету расходов, произведенных членами магистрата» ${ }^{61}$. Из приложенного к письму исправляющего должность городского головы К. Когбетлиева видно, что заседания опекунов происходили совместно с городским головой, а также, что магистрат именно к ним обращался с просьбой о дополнительных сборах с населения (по добровольной складке) для компенсации понесенных членами магистрата расходов и призывом «увеличить по росписи число служащих в магистрате канцелярских служителей, десятских и добавить одного сторожа, с назначением им жалованья» ${ }^{62}$. В обеих просьбах было отказано, а относительно последнего пункта - об увеличении штатов магистрату - было указано, что «обстоятельство это не относится до суждения и разрешения общественного управления» ${ }^{63}$.

Восстановление института опекунов при городском голове стало одним из элементов в общем процессе подготовки и проведения реформ, а по сути - упразднением армянского самоуправления вопреки упорному нежеланию нахичеванцев поступиться дарованными Екатериной II «правами и преимуществами», к числу которых относилось и армян-

\footnotetext{
${ }^{57}$ НАА. Ф. 139. Оп. 1. Д. 249. Л. 45 об. -46.

${ }^{58}$ НАА. Ф. 139. ОП. 1. Д. 207. Л. 6.

${ }^{59}$ НАА. Ф. 139. Оп. 1. Д. 207. Л. 17-17 об.

${ }^{60}$ НАА. Ф. 139. Оп. 1. Д. 207. Л. 20 об., 21.

${ }^{61}$ НАА. Ф. 139. Оп. 1. Д. 223. Л. 28.

${ }^{62}$ НАА. Ф. 139. Оп. 1. Д. 223. Л. 29.

${ }^{63}$ НАА. Ф. 139. Оп. 1. Д. 223. Л. 29 об.
} 
ское самоуправление. В результате реформ Нахичевань-на-Дону утратила остатки автономии и превратилась в заштатный российский город с преимущественно армянским населением.

\section{Список литературы}

1. Алексеев К. 1870. Изложение законоположений в Армянском судебнике. М., Университетская типография, 89.

2. Бархударян В.Б. 1996. История армянской колонии Новая Нахичевань (1779-1917). Ереван: «Айастан», 528.

3. Батиев Л.В. 2018. Полицейская служба в Нахичевани-на-Дону (конец XVIII-XIX вв.). Вопросы арменоведения. 3 (115), 3-16.

4. Батиев Л.В., Казаров С.С. 2018. Ново-Нахичеванский магистрат: происхождение, структура, функции. Былые годы. 2, 518-527.

5. Богданян М. 1989. Из прошлого. О переселении армян из Крыма. 2-е изд. Ростов н/Д: Рост. кн. изд-во, 16.

6. Келле-Шагинов С. 2012. История семьи из бывшего города Нахичевани-на-Дону в воспоминаниях ушедших поколений. Relga №7 [245] 01.05 URL: https://husisapail.wordpress.com/2012/05/01/сергей-келле-шагинов-история-семьи-из/ Дата обращения -3 ноября 2019 г.

7. Келле-Шагинов И.М. 2014. Моя единственная жизнь. Дневники и воспоминания. Ростов-на-Дону, Старые русские, 320.

8. Патканян Г. 1917. История Новой Нахичевани. Нахичевань-на-Дону, Б.и.123. (на арм. яз.)

9. Полное собрание законов Российской империи. Собрание 1-е (ПС3-I). 1830. СПб., Тип. 2-го Отд-ния Собств. Е. И. В. Канцелярии. Т. 20. № 14942.

10. ПСЗ-І. Т. 22, № 16187.

11. Полное собрание законов Российской империи. Собрание 2-е (ПС3-II). 1868. СПб., Тип. 2-го Отд-ния Собств. Е. И. В. Канцелярии. Т. 43. № 45541.

12. ПСЗ-II. Т. 13. № 10976. 1838 г.

13. Свод законов Российской империи. 1857. Т. 3. Уставы о службе гражданской. СПб., Тип. Второго Отделения Собственной Е. И. В. Канцелярии, 1057.

14. Сидоров В.С. 1994-1999. История старого Ростова и Нахичевани-на-Дону: В 5 т. Ростов н/Д: Изд-во ДГПБ.

15. Смирнов В.В. 2018. Летопись Нахичевани-Дону: в историческом, бытописательном, статистическом и иллюстративном интерьерах с приложениями, включающими важные, полезные и интересные сведения. Ростов-на-Дону: ЗАО «Книга». 456.

16. Судебно-статистические сведения и соображения о введении Судебных уставов 20 ноября 1864 года (по 32 губерниям). Ч. І. 1866. СПб., 483.

17. Шахазиз Е. 1903. Исторические зарисовки. - Тифлис, Типография Ротинянца. 239 (на арм. яз.).

\section{References}

1. Alekseev K. 1870. Izlozhenie zakonopolozhenij v Armyanskom sudebnike [Statement of Laws in the Armenian Criminal Code]. M., Universitetskaya tipografiya, 1870. 89 (in Russian).

2. Barhudaryan V.B. Istoriya armyanskoj kolonii Novaya Nahichevan' (1779-1917) [History of the Armenian colony New Nakhichevan (1779-1917)]. Erevan, «Ajastan». 1996, 528 (in Russian).

3. Batiev L.V. 2018. Policejskaya sluzhba v Nahichevani-na-Donu (konec XVIII-XIX vv.) [Police service in Nakhichevan-on-Don (late XVIII-XIX centuries)]. Voprosy armenovedeniya. 3 (115), 3-16 (in Russian).

4. Batiev L.V., Kazarov S.S. 2018. Novo-Nahichevanskij magistrat: proiskhozhdenie, struktura, funkcii [Novo-Nakhichevan magistrate: origin, structure, functions]. Bylye gody. 2, 518-527 (in Russian).

5. Bogdanyan M. Iz proshlogo. O pereselenii armyan iz Kryma [From the past. About the resettlement of Armenians from Crimea]. 2-e izd. Rostov n/D: Rost. kn. izd-vo, 1989. 16 (in Russian).

6. Kelle-SHaginov S. 2012. Istoriya sem'i iz byvshego goroda Nahichevani-na-Donu v vospominaniyah ushedshih pokolenij [The story of a family from the former city of Nakhichevan-on-Don in the recollections of bygone generations]. Relga № 7 [245] 01.05 // URL: 
https://husisapail.wordpress.com/2012/05/01/sergej-kelle-shaginov-istoriya-sem'i-iz/ Data obrashcheniya 3 noyabrya 2019 g. (in Russian).

7. Kelle-Shaginov I.M. Moya edinstvennaya zhizn'. Dnevniki i vospominaniya. Rostov-naDonu [My only life. Diaries and memories], Starye russkie, 2014, 320 (in Russian).

8. Patkanyan G. 1917. Istoriya Novoj Nahichevani [History of New Nakhichevan]. Nahichevan'-na-Donu, B. i., 123 (in Armenian).

9. Polnoe sobranie zakonov Rossijskoj imperii. Sobranie 1-e (PSZ-I). 1830. SPb., Tip. 2-go Otd-niya Sobstv. E. I. V. Kancelyarii. T. 20. № 14942.

10. PSZ-I. T. 22, № 16187.

11. Polnoe sobranie zakonov Rossijskoj imperii. Sobranie 2-e (PSZ-II). 1868. SPb., Tip. 2-go Otd-niya Sobstv. E. I. V. Kancelyarii. T. 43. № 45541.

12. PSZ-II. T. 13. № 10976. SPb. 1838.

13. Svod zakonov Rossijskoj imperii. T. 3. Ustavy o sluzhbe grazhdanskoj. SPb., Tip. 2-go Otdniya Sobstv. E. I. V. Kancelyarii. 1857, 1057.

14. Sidorov V.S. 1994-1999. Istoriya starogo Rostova i Nahichevani-na-Donu: V 5 t. [The history of old Rostov and Nakhichevan-on-Don]. Rostov n/D: Izd-vo DGPB (in Russian).

15. Smirnov V.V. 2018. Letopis' Nahichevani-Donu: v istoricheskom, bytopisatel'nom, statisticheskom i illyustrativnom inter'erah s prilozheniyami, vklyuchayushchimi vazhnye, poleznye $\mathrm{i}$ interesnye svedeniya [Chronicle of Nakhichevan-Don: in historical, descriptive, statistical and illustrative interiors with applications that include important, useful and interesting information]. Rostov-na-Donu: ZAO «Kniga», 456 (in Russian).

16. Sudebno-statisticheskie svedeniya i soobrazheniya o vvedenii Sudebnyh ustavov 20-go noyabrya 1864 goda (po 32 guberniyam). CH. I. 1866. SPb., 483.

17. Shahaziz E. 1903. Istoricheskie zarisovki [Historical essays]. - Tiflis, Tipografiya Rotinyanca, 239 (in Armenian).

\section{Ссылка для цитирования статьи Link for article citation}

Батиев Л.В. 2020. Двадцать четыре попечителя Нахичевани-на-Дону (из истории одного полузабытого органа). Via in tempore. История. Политология, 47 (2): 318-326. DOI 10.18413/2687-0967-2020-47-2-318-326.

Batiev L.V. 2020. Twenty-four trustees of Nakhichevani-on-Don (from the history of one semi-forgotten authority). Via in tempore. History and political science, 47 (2): 318-326 (in Russian). DOI 10.18413/2687-0967-2020-47-2-318-326. 